\section{Anđela Bučević}

Zagreb

Ana Bonetti

University of Zagreb, Faculty of Education and

Rehabilitation Sciences, Department of Speech and

Language Pathology

\section{Luka Bonetti}

University of Zagreb, Faculty of Education and Rehabilitation Sciences, Department of Hearing

Impairments

\section{The voice quality of sports coaches}

\begin{abstract}
The aim of this research paper was to examine the voice quality of sports coaches using the objective (acoustic) method. A total of 28 sports coaches (mean age 28.58, SD=5.08), from the City of Zagreb participated in this research. Recordings of the phonation of the vowel /a/ before and after one training session were obtained and analyzed using the PRAAT Program. Mean, minimal and maximal values of fundamental frequency, shimmer, jitter and harmonics-to-noise ratio were observed. The statistical analyses showed no statistically significant difference in acoustic voice quality of male and female coaches before and after the training session, or between male and female coaches. However, intraindividual differences among participants were observed, which may be significant in terms of their potential to affect the quality of their voices in the future.
\end{abstract}

Keywords: voice quality sports coaches - acoustic analysis 


\section{INTRODUCTION}

Voice disorders are more often seen among vocal professionals - individuals who need their voice to carry out any kind of professional performance - than the nonprofessional voice users. Vocal professionals use their voice in an "athletic" manner because they expose it to extensive and strenuous tasks during their working hours. Previous research has shown that $50-90 \%$ of vocal professionals experience dysphonia or vocal fatigue throughout their working life (Smith, Lemke, Taylor, Kirchner \& Hoffman, 1998) and recent data confirms that vocal professionals are the most vulnerable group regarding the risk of developing a voice disorder (Byeon, 2017).

Sports coaches are vocal professionals because their voice is an essential component of their work, and research shows that they often face various voice related problems. It has been reported that sports coaches have very little knowledge about voice and vocal hygiene, that they do not take care of the health of their voice, have certain habits which can negatively influence their vocal health and often encounter symptoms of vocal fatigue and experience dysphonia (Trout \& Mccoll, 2007; Penteado \& Bernardi da Silva, 2014). Moreover, majority of sports coaches are regularly exposed to various conditions which can further compromise their vocal health, facing the risk factors such as: loud speaking and shouting at long distances and in an environment with poor acoustics, speaking during exercises, prolonged voice use and job-related stress (O’Neill \& McMenamin, 2014). Increased stress due to a desire for athletic success is an important factor, since its emotional effects can increase vocal load and consequently provoke the changes in vocal quality and raise the risk of development of a voice disorder (Kooijman et al., 2006; Long, Williford, Olson \& Wolfe, 1998).

It is a known fact that voice disorders can develop as the result of a long-term accumulation of short-term intense activities traumatic to the vocal cords (Cielo, Ribeiro \& Hoffmann, 2015), like yelling and screaming, especially in situations with loud background noise. It can be assumed that most of sport coaches use their voice in this or similar manner, i. e. intensively during relatively short periods of the day (during a match, contest or training), in acoustically very unfavorable surroundings (outdoors or in noisy sport halls) and that this kind of vocal usage will have objectively (acoustically) recognizable negative short-term effects. If so, appropriate preventive activities (like education on vocal hygiene) are advisable for sports coaches, considering that repeating short-term vocal trauma can lead to more serious functional and even organic consequences (Baker, 2016; Van Houtte, Van Lierde \& Claeys, 2011; Altman, Atkinson \& Lazarus, 2005; Roy, 2003).

The aim of this paper was to objectively examine possible short-term changes in voice quality of sports coaches before and after training sessions, with the purpose of gaining the insight into:

a) the potential of their usual daily vocal load to induce the acoustic voice quality changes, and

b) the ensuing need of the prevention of voice disorders in this working population (as proposed by Cielo et al., 2015).

Accordingly, the paper hypothesized a statistically significant difference in acoustic parameters of sports coaches' voices before and after the training.

\section{METHODS}

\section{Participants}

A total of 28 sports coaches (14 females and 14 males), aged between 23 and 42 years (mean age 28.58, SD=5.08), participated in the study. Participants regularly coached groups of 5 or more persons (children, adolescents or adults), 2 or more times a week, for at least 1 hour per training session, in the following sports: football (5 coaches), tennis (7 coaches), taekwondo (1 coach), swimming (1 coach) and other indoor sports like aerobics, zumba, dance, etc. (14 coaches). While participating in the study, coaches did not report any vocal or other health related complaints. According to their own statements, none of the participants was educated on voice abuse and/or practiced any methods for minimization of voice abuse or misuse.

\section{Voice measures}

The following standard objective voice measures (Naufel de Felippe, Grillo \& Grechi, 2006) were selected regarding the defined aim of the study: Fundamental Frequency $\left(\mathrm{F}_{0}\right.$, in $\mathrm{Hz}$ ), Jitter (JITT, in \%), Shimmer (SHIMM, in dB) and Harmonic-to-Noise Ratio (HNR, in dB). Each of the selected measures was sampled in the premises where training was held, individually, before and after the training, in empty locker rooms with closed windows and doors and other potential noise sources neutralized. Recordings of sustained phonations of the vowel / a/ were obtained using the digital recorder TASCAM DR-05, with the microphone placed 15 $\mathrm{cm}$ from the mouth of each participant.

\section{Data processing}

Recorded samples of the sustained phonations were arranged for further acoustic analysis using the Adobe Audition 1.5 computer program, for which sampling rate of $44100 \mathrm{~Hz}$ and the dynamic range of 16 bits were used. Acoustic analysis of the arranged individual voice samples was performed on their 5 seconds long mid-section using the PRAAT program (Boersma \& Weenink, 2018). The acoustic analysis included the readings of the mean, minimum and maximum $\mathrm{F}_{0}$, JITT, SHIMM and HNR values.

Statistical analysis of the obtained acoustic data was carried out subsequently. Firstly, the descriptive analysis was performed, followed by the normality of distribution testing (for which the Shapiro-Wilk test was used); nonparametric Sign test was used to test the differences in acoustic data before and after the training. The mean, minimum and maximum $\mathrm{F}_{0}$ was analyzed separately for female and male groups of participants due to the gender specific character of this acoustic measure (Stathopoulos, Huber \& Sussman, 2011). The adopted level of significance for statistical analysis was $\mathrm{p}<0.05$. 


\section{RESULTS AND DISCUSSION}

Tables 1 and 2 present the results of descriptive analysis of the observed acoustic voice measures before and after the training.

Mean values for all of observed acoustic voice measures (except the $\mathrm{F}_{0}$, which was analyzed in respect to gender) appear to be normal before the training for participants, as well for female and male participants separately (Table 1). However, the individual entries in Table 1 give more detailed information on the voice quality of participants before the training: 1 female participant and 1 male participant have deviating values on two acoustic measures - SHIMM and HNR - with SHIMM somewhat higher than the reference value of $0.35 \mathrm{~dB}$ and the HNR somewhat lower than the reference value of $20 \mathrm{~dB}$ (Boersma \& Weenink, 2018). Slightly lower HNR values can be observed in 4 other female and 2 other male participants. Deviation from the reference SHIMM value can be observed in 1 male participant, while the observed values of JITT are within the normal range across the whole sample of 28 participants (Fernand, 2012; in Botha, Ras, Abdoola \& Van der Linde, 2017).

Table 1: The acoustic voice measures obtained before the training (the number 1 by the variable code indicates the first measurement, before the training)

\begin{tabular}{|c|c|c|c|c|c|}
\hline Gender & AM & $\mathbf{M}$ & Min & $\operatorname{Max}$ & SD \\
\hline \multirow{4}{*}{$\begin{array}{c}\text { Males } \\
(\mathrm{N}=14)\end{array}$} & $\mathrm{F}_{0} 1(\mathrm{~Hz})$ & 119.33 & 92.26 & 175.87 & 23.81 \\
\hline & $\begin{array}{c}\text { JITT1 } \\
(\%)\end{array}$ & 0.26 & 0.14 & 0.55 & 0.11 \\
\hline & $\begin{array}{c}\text { SHIMM1 } \\
\text { (dB) }\end{array}$ & 0.29 & 0.15 & 0.39 & 0.07 \\
\hline & $\begin{array}{l}\text { HNR1 } \\
\text { (dB) }\end{array}$ & 22.41 & 15.13 & 26.99 & 3.35 \\
\hline \multirow{4}{*}{$\begin{array}{c}\text { Females } \\
(\mathrm{N}=14)\end{array}$} & $\mathrm{F}_{0} 1(\mathrm{~Hz})$ & 220.22 & 179.07 & 281.51 & 29.07 \\
\hline & $\begin{array}{c}\text { JITT1 } \\
(\%)\end{array}$ & 0.30 & 0.15 & 0.56 & 0.12 \\
\hline & $\begin{array}{l}\text { SHIMM1 } \\
(\mathrm{dB})\end{array}$ & 0.26 & 0.13 & 0.44 & 0.08 \\
\hline & $\begin{array}{l}\text { HNR1 } \\
\text { (dB) }\end{array}$ & 21.99 & 17.57 & 27.95 & 3.32 \\
\hline \multirow{3}{*}{$\begin{array}{c}\text { All } \\
(\mathrm{N}=14)\end{array}$} & $\begin{array}{c}\text { JITT1 } \\
(\%)\end{array}$ & 0.28 & 0.14 & 0.56 & 0.12 \\
\hline & $\begin{array}{l}\text { SHIMM1 } \\
\text { (dB) }\end{array}$ & 0.28 & 0.13 & 0.44 & 0.07 \\
\hline & $\begin{array}{l}\text { HNR1 } \\
\text { (dB) }\end{array}$ & 22.20 & 15.13 & 27.95 & 3.28 \\
\hline
\end{tabular}

Legend:

$\mathrm{N}=$ the number of the participants; $\mathrm{AM}=$ acoustic measure; $\mathrm{M}=$ mean; $\mathrm{Min}=$ minimal value; $\mathrm{Max}=$ maximal value; $\mathrm{SD}=$ standard deviation

After the training, mean values for most of the observed acoustic voice measures deteriorated and reached borderline values (Table 2). Again, the individual entries were inspected to get more detailed information on the voice quality of participants after the training. This inspection showed that numerous individual entries in Table 2 deviate from the orderly values after the training:
1 male participant showed deviations on all of the observed acoustic voice measures ( $\mathrm{F}_{0}$, JITT, SHIMM and HNR), 3 male and 3 female participants showed deviations on 2 of the observed acoustic voice measures (HNR and SHIMM), and 3 male and 2 female participants on only one of the observed acoustic voice measures (HNR or SHIMM).

Table 2: The acoustic voice measures obtained after the training (the number 2 by the variable code indicates the second measurement, after the training)

\begin{tabular}{|c|c|c|c|c|c|}
\hline Gender & AM & M & Min & Max & SD \\
\hline \multirow{4}{*}{$\begin{array}{c}\text { Males } \\
(\mathrm{N}=14)\end{array}$} & $\mathrm{F}_{0} 2(\mathrm{~Hz})$ & 121.74 & 99.01 & 162.03 & 16.23 \\
\hline & $\begin{array}{c}\text { JITT2 } \\
(\%)\end{array}$ & 0.32 & 0.12 & 1.08 & 0.24 \\
\hline & $\begin{array}{l}\text { SHIMM2 } \\
\text { (dB) }\end{array}$ & 0.33 & 0.13 & 0.55 & 0.13 \\
\hline & $\begin{array}{l}\text { HNR2 } \\
\text { (dB) }\end{array}$ & 21.54 & 15.27 & 26.06 & 3.32 \\
\hline \multirow{4}{*}{$\begin{array}{c}\text { Females } \\
(\mathrm{N}=14)\end{array}$} & $\mathrm{F}_{0} 2(\mathrm{~Hz})$ & 211.65 & 179.77 & 248.11 & 23.47 \\
\hline & $\begin{array}{c}\text { JITT2 } \\
(\%)\end{array}$ & 0.26 & 0.10 & 0.46 & 0.12 \\
\hline & $\begin{array}{c}\text { SHIMM2 } \\
\text { (dB) }\end{array}$ & 0.29 & 0.13 & 0.81 & 0.19 \\
\hline & $\begin{array}{l}\text { HNR2 } \\
\text { (dB) }\end{array}$ & 23.12 & 16.24 & 28.50 & 3.77 \\
\hline \multirow{3}{*}{$\begin{array}{c}\text { All } \\
(\mathrm{N}=28)\end{array}$} & $\begin{array}{c}\text { JITT2 } \\
(\%)\end{array}$ & 0.29 & 0.10 & 1.08 & 0.19 \\
\hline & $\begin{array}{l}\text { SHIMM2 } \\
\text { (dB) }\end{array}$ & 0.31 & 0.13 & 0.81 & 0.16 \\
\hline & $\begin{array}{l}\text { HNR2 } \\
\text { (dB) }\end{array}$ & 22.33 & 15.27 & 28.50 & 3.58 \\
\hline
\end{tabular}

Legend:

$\mathrm{N}=$ the number of the participants; $\mathrm{AM}=$ acoustic measure; $\mathrm{M}=$ mean; Min $=$ minimal value; $\mathrm{Max}=$ maximal value $\mathrm{SD}=$ standard deviation

The results of the Sign Test, used to compare the average observed acoustic voice measures before and after the training, are shown in Table 3. These results show that the comparison of the mean $\mathrm{F}_{0}$, JITT, SHIMM and HNR was not statistically important, i. e. the differences in the observed acoustic voice measures before and after training are not significant. Therefore, the hypothesis of this paper can be rejected.

Table 3: The testing of differences in the observed acoustic voice measures before and after the training

\begin{tabular}{|c|c|c|c|}
\hline & Percent $-\mathbf{v}<\mathbf{V}$ & $\mathbf{Z}$ & $\mathbf{p}$ \\
\hline $\begin{array}{c}\mathbf{F}_{0} \text { 1 vs. } \text { F }_{0} \mathbf{2} \\
\text { (Females) }\end{array}$ & 42.857 & 0.267 & 0.789 \\
\hline $\begin{array}{c}\text { F }_{0} \text { 1 vs. } \text { F }_{0} \mathbf{2} \\
\text { (Males) }\end{array}$ & 57.143 & 0.267 & 0.789 \\
\hline JITT1 vs. JITT2 & 39.286 & 0.945 & 0.345 \\
\hline SHIM1 vs. SHIM2 & 50.000 & -0.189 & 0.850 \\
\hline HNR1 vs. HNR2 & 53.571 & 0.189 & 0.850 \\
\hline
\end{tabular}


The absence of a statistically significant difference between two measurements (before and after the training) suggests that sports coaches in general do not overuse or abuse their voices during typical training sessions. Nevertheless, even though the results of Sign Test are not significant, trends can be seen in some participants, and intraindividual differences among participants need to be taken into consideration. The observed individual changes of the acoustic voice measures after the training deserve attention because they reflect the strain some of the participants usually impose on their voice and, as such, may be significant in terms of their potential to affect the quality of participants' voices in the years to come. These individual acoustic voice changes after the training may not yet be significant, but could be the ground on which more serious acoustic voice changes could develop in the future. This could especially be true for participants whose individual acoustic parameters mildly deviated in the first measurement (before the training), which could be interpreted as an early and discrete sign of the change of the manner of voice production due to voice overuse and/or abuse.

These and some other results (Dallaston \& Rumbach, 2015) suggest that everyday professional engagement can induce discrete changes in the values of acoustic voice measures in some sports coaches; however, better understanding of their long-term consequences still needs to be acquired. This can be accomplished by overcoming some of the limitations of this research. For instance, this research recruited a relatively small number of subjects to explain possible gender differences and did not inspect the possible relationship of acoustic voice parameters and the number of hours sports coaches spend on training sessions per week, the amount of noise present during the training session, surrounding acoustic and other settings (indoor vs. outdoor training sessions) or the number of working years. Moreover, the functional impact of the observed discrete acoustic voice changes on professional performance could be better explained by the subjective voice assessment, which was also not performed in this study. Given that sports coaches have high rates of vocal complains (Newman \& Kersner, 1998), their professional performance and their quality of life could be affected even by discrete acoustic changes in their voice (Buckley, O'Halloran \& Oates, 2011), as is the case with other vocal professionals (Murry, Zschommler \& Prokop, 2009).

The vocal strain observed in some participants of this study may be interpreted as the confirmation of their insufficient knowledge about vocal hygiene, which could protect their voice from harmful habits such as vocal overuse or abuse in acoustically unfavorable environments. This notion arises from the observed negative changes in individual acoustic voice measures after the training, which are indicative of the lack of vocal warm-up before the training (Ribeiro, Frigo, Bastilha \& Cielo, 2016) or the use of harmful vocal production techniques during everyday work.

\section{CONCLUSION}

Sports coaches are vocal professionals because their voice plays a very important role in their everyday work. Because of the high daily vocal usage in unfavorable conditions, they face potential risk of developing poor vocal techniques, and consequently a voice disorder. Considering that discrete negative acoustic changes were observed in this study in individual sport coaches after their usual daily vocal load, the question arises whether preventive actions are necessary among these vocal professionals. Individual results of this study may be interpreted as indicative of the need to raise awareness among sports coaches of the importance of voice and its health on their professional performance and the ensuing quality of life. Systematical education of sports coaches about voice and its (proper) production, vocal hygiene, surrounding conditions, as well as communication, socio-emotional and financial consequences of voice disorders, seems to be the most practical and efficient preventive option.

\section{REFERENCES}

1) Altman, K. W., Atkinson, C. \& Lazarus, C. (2005). Current and Emerging Concepts in Muscle Tension Dysphonia: A 30-Month Review. Journal of Voice, 19(2), 261267.

2) Baker, J. (2016). Functional voice disorders: Clinical presentations and differential diagnosis. Handbook of Clinical Neurology, 139, 389-405.

3) Boersma, P. \& Weenink, D. (2018). Praat: doing phonetics by computer [Computer program]. Version 6.0.40, retrieved 11 May 2018 from http://www.praat.org/

4) Botha, A., Ras, E., Abdoola, S. \& Van der Linde, J. (2017). Dysphonia in adults with developmental stuttering: A descriptive study. South African Journal of Communication Disorders, 64(1), e1-e7. doi: 10.4102/sajcd.v64i1.347.

5) Buckley, K., O'Halloran, P. \& Oates, J. (2011). Voice and vocal health in elite sports coaching: considerations for elite football coaching staff. British Journal of Sports Medicine, 45, 337-338.

6) Byeon, H. (2017). Occupational risk for voice disorders: Evidence from a Korea national cross- sectional survey. Logopedics-Phoniatrics-Vocology, 42, 1, 39-43.

7) Cielo, C.A., Ribeiro, V. V. \& Hoffmann, C. F. (2015). Vocal symptoms of future professional voice users. Revista CEFAC: Atualizacao Cientifica em Fonoandiologia e Educacao, 17(1), 34-43.

8) Dallaston, K. \& Rumbach, A. F. (2015). Vocal Performance of Group Fitness Instructors Before and After Instruction: Changes in Acoustic Measures and Self- Ratings. Journal of Voice, 30(1), 127.e1-e8.doi: 10.1016/j.jvoice.2015.02.007.

9) Kooijman, P. G., de Jong, F. I., Thomas, G., Huinck, W., Donders, R., Graamans, K. \& Schutte, H. K. (2006). Risk factors for voice problems in teachers. Folia Phoniatrica et Logopaedica, 58(3), 159-174.

10) Long, J., Williford, H. N., Olson, M. S. \& Wolfe, V. (1998). Voice problems and risk factors among aerobics instructors. Journal of Voice, 12(2), 197-207.

11) Murry, T., Zschommler, A. \& Prokop, J. (2009). Voice handicap in singers. Journal of Voice, 23(3), 376-379.

12) Naufel de Felippe, A. C., Grillo, M. H. \& Grechi, T. H. (2006). Standardization of acoustic measures for normal voice patterns. Brazilian Journal of Otorbinolaryngology, 72(5), 659-64.

13) Newman, C. \& Kersner, M. (1998). Voice problems of aerobics instructors: implications for preventative training. Logopedics-Phoniatrics-Vocology, 23(4), 177-180. 
14) O’Neill, J. \& McMenamin, R. (2014). Voice use in professional soccer management. Logopedics-PhoniatricsVocology, 39(4), 169-178.

15) Penteado, R. Z. \& Bernardi da Silva, N. (2014). Voice and work conditions of soccer coaches and physical trainers. Disturbios da Comunicacao, 26(4), 790-799.

16) Roy, N. (2003). Functional dysphonia. Current Opinion in Otolaryngology \& Head and Neck Surgery, 11, 144-148.

17) Smith, E., Lemke, J., Taylor, M., Kirchner, H. L. \& Hoffman, H. (1998). Frequency of voice problems among teachers and other occupations. Journal of Voice, 12(4), 480488.

18) Stathopoulos, E. T., Huber, J. E. \& Sussman, J. E. (2011). Changes in acoustic characteristics of the voice across the life span: measures from individuals 4-93 years of age. Journal of Speech, Language and Hearing Research, 54(4), 1011-21.

19) Trout, J. \& Mccoll, D. (2007). Vocal Health for Physical Educators. Journal of Physical Education, Recreation and Dance, 78(8), 12-14.

20) Van Houtte, E., Van Lierde, K. \& Claeys, S. (2011).

Pathophysiology and Treatment of Muscle Tension Dysphonia: A Review of the Current Knowledge. Journal of Voice, 25(2), 202-207.

21) Ribeiro, V. V., Frigo, L. F., Bastilha, G. R. \& Cielo, C. A. (2016). Vocal warm-up and cool-down: systematic review. Revista CEFAC: Atualizacao Cientifica em Fonoandiologia e Educacao, 18(6), 1456-1465. 